\title{
SOROEPIDEMIOLOGIA DA LEUCEMIA BOVINA (LB) EM BOVINOS CURRALEIROS DOS ESTADOS DE GOIÁS E TOCANTINS, BRASIL.
}

\author{
Raquel SoAres Juliano ${ }^{1}$, Maria Clorinda Soares Fioravanti ${ }^{2}$, Wilia Marta Elsner
}

Diederichsen de Brito ${ }^{2}$, URbano Gomes Pinto de ABreu ${ }^{1}$, SAURA NAYANE de SouZA ${ }^{3}$

${ }^{1}$ Pesquisadores Doutores da EMBRAPA Pantanal, Corumbá, MS, Brasil. - raquel.juliano@embrapa.br ${ }^{2}$ Professoras Doutoras da Universidade Federal de Goiás, Goiânia, GO, Brasil.

${ }^{3}$ Pós-Graduanda da Universidade Federal de Goiás, Goiânia, GO, Brasil.

\section{RESUMO}

Com o objetivo de verificar a ocorrência da leucose enzoótica (LB) em bovinos Curraleiros, foram amostrados soros sanguíneos de um total de 1051 animais pertencentes a 11 rebanhos localizados nos Estados de Goiás e 12 em Tocantins. O diagnóstico sorológico de LB foi realizado pelo método de imunodifusão em gel de ágar (IDGA). A taxa total de sororeagentes foi $21,1 \%$
(222/1051). Em Tocantins foram encontrados 27,8\% (136/489) de sororreagentes, número significativamente maior que em Goiás, onde foram encontrados $15,3 \%$ (86/562). A sororreatividade foi maior em fêmeas que em machos, 23,3\% (198/852) e $11,8 \% \quad(23 / 195)$, respectivamente, e em animais com idade superior a 48 meses.

PALAVRAS-CHAVE: bovinos naturalizados, epidemiologia, leucose enzoótica bovina.

\section{SEROEPIDEMIOLOGY OF BOVINE LEUKAEMIA (LB) IN CURRALEIRO CATTLE BREED FROM GOIÁS AND TOCANTINS STATES}

\section{ABSTRACT}

Aiming to verify bovine leukaemia (BL) occurrence in Curraleiro cattle breed, sera of 1051 animals were sampled from Goias $(n=11)$ and Tocantins $(n=12)$ states. BL serological diagnosis was performed by agar gel immunodiffusion method (AGID). The total occurrence rate was $21.1 \%(222 / 1051)$. In Tocantins it was $27.8 \%$

KEYWORDS: Epidemiology, leucosis, naturalized bovine.

\section{INTRODUÇÃO}

Os animais que deram origem ao gado Curraleiro foram trazidos da Península Ibérica para o Brasil pelos portugueses na época do
(136/489) occurrence was observed, higher value than in Goias, where $15.3 \%$ (86/562) occurrence was found. The serum reactivity was higher in females than in males, $23.3 \%(198 / 852)$ and $11.8 \%$ (23/195), respectively, and in animals older than 48 months old.

descobrimento ${ }^{1}$ e esta raça atualmente pode ser encontrada em rebanhos nos Estados brasileiros do Maranhão, Piauí, Goiás e Tocantins. Os criadores ressaltam a rusticidade, o baixo custo de produção e a baixa exigência nutricional como qualidades 
indiscutíveis na criação desses animais ${ }^{2}$.

Existem poucas informações disponíveis sobre seu efetivo rebanho nacional. No ano de 2005, a Associação Brasileira de Criadores de Curraleiro (ABCC) estimou um total de 2008 animais em 22 criatórios cadastrados ${ }^{3}$, caracterizando-se como uma população vulnerável ao risco de extinção, segundo critério da $\mathrm{FAO}^{4}$ que leva em consideração um número de fêmeas em reprodução entre 1000 e 5000 indivíduos. Esse fato motivou um esforço conjunto entre Universidades, diferentes unidades da Embrapa, $\mathrm{ABCC}$ e vários criadores dessa raça a trabalharem com afinco em projetos de pesquisas relacionados à caracterização dos sistemas produtivos e seus aspectos sanitários, com a finalidade de reunir informações para definir estratégias de conservação e uso desse patrimônio genético. Com isso, foram localizados posteriormente, 49 criatórios distribuídos nos Estados de Goiás, Tocantins, Pará, Bahia e Piauí, totalizando 3692 animais ${ }^{5}$.

A leucemia bovina (LB) é uma enfermidade infectocontagiosa de caráter crônico, causada pelo vírus da leucemia bovina (VLB), que se encontra disseminado nos rebanhos bovinos de todo o mundo. A principal forma de transmissão da LB é por via iatrogênica, porque o vírus presente no sangue de um animal portador pode ser transmitido a um animal não infectado por intermédio de procedimentos cirúrgicos, injeções, palpação retal ou utilização de fômites contaminados. As fêmeas infectadas podem transmitir o VLB aos seus bezerros durante o parto ou pelo colostro ${ }^{6}$.

A infecção pelo VLB leva ao aparecimento de leucocitose com linfocitose persistente em aproximadamente $30 \%$ dos animais infectados, que não apresentam nenhuma evidencia clínica. Entretanto, 0,5 a 5,0\% dos bovinos infectados, com idade entre 4 e 8 anos, apresentam a forma tumoral da doença, com o desenvolvimento de linfossarcomas ${ }^{6}$.

Apesar de os portadores assintomáticos serem importantes na disseminação do vírus no rebanho, existem controvérsias sobre o caráter imunossupressor do VLB nesses animais e sobre a queda na produtividade. Garcia et al. ${ }^{7}$ e Birgel Jr. et al. ${ }^{8}$ não encontraram interferência na imunidade humoral e celular, enquanto Azedo et al. ${ }^{9}$ identificaram alterações funcionais em fagócitos mononucleares de animais sororreagentes. D'Angelino et al. ${ }^{10}$ ressaltaram a possibilidade de quedas na produção leiteira em animais sororreagentes, porém não foram observadas diferenças nos índices reprodutivos. Em rebanhos leiteiros dos Estados Unidos, foi estimada queda de $3 \%$ na produção, significando perda de US\$ 59 por fêmea nos rebanhos sororreagentes ${ }^{11}$.

A importância econômica relacionada à enfermidade decorre de perdas na exportação para mercados que requerem bovinos livres da infecção; custos com o diagnóstico e o tratamento das complicações dos animais com linfossarcoma; descarte prematuro ou morte de animais clinicamente afetados e condenação de carcaças em frigoríficos com serviço de inspeção. Embora o risco de transmissão pelo sêmen congelado e embriões seja mínimo, para atender ao comércio internacional, o país importador pode exigir um atestado de que esse material seja oriundo de animais não reagentes, colhido, processado e armazenado em conformidade com as exigências da Organização Mundial de Saúde Animal (OIE) e da Sociedade Internacional de Transferência de Embriões (IETS) ${ }^{12}$. Nesse caso, a análise de risco assume grande importância na definição das condições necessárias tanto para evitar a disseminação de doenças quanto para evitar restrições sanitárias relacionadas ao comércio ${ }^{13}$.

Diante da intenção de expandir a população do gado Curraleiro e de incentivar a produção de alimentos de origem animal, principalmente para populações de baixa renda, residentes em regiões de condições desfavoráveis como as do cerrado e do agreste brasileiro, e de modo a atender às exigências para comercialização dentro e fora do país, torna-se necessário obter dados referentes aos aspectos sanitários desses animais. Sendo assim, este estudo teve como objetivo pesquisar anticorpos contra o VLB em rebanhos bovinos Curraleiros e correlacioná-los com possíveis fatores de risco associados à infecção por esse vírus.

\section{MATERIAL E MÉTODOS}

Durante o ano de 2006 foram coletadas amostras de soro de um total de 1051 animais, machos $(n=195)$ e fêmeas $(n=852)$, com idade entre 4 dias a 22 anos, pertencentes a rebanhos de bovinos da raça Curraleiro, localizados nos Estados de Goiás $(n=11)$ e Tocantins $(n=12)$. Houve perda de informação relacionada ao sexo de quatro animais.

A princípio, optou-se por amostrar todas as 
propriedades descritas por Boaventura et al. ${ }^{3}$, como um estudo censitário. Entretanto, respeitouse o direito de participação voluntária dos produtores e, por meio desse primeiro contato, outros rebanhos foram localizados, definindo um novo efetivo de rebanho, descrito posteriormente por Fioravanti et al. ${ }^{5}$.

A amostragem de indivíduos examinados por propriedade variou entre 10 e $100 \%$, na dependência da maior ou menor facilidade em recolher os animais, tendo em vista a extensão de algumas propriedades, a baixa densidade populacional e o fato de esses animais habitarem, na maioria dos casos, áreas de campo com mata. Sendo assim, foram amostrados todos os animais que puderam ser recolhidos no curral sem que fosse feito um cálculo amostral para isso.

As amostras de sangue foram colhidas por venopunção jugular em tubos sem anticoagulante e o soro obtido foi utilizado para a pesquisa de anticorpos contra o BLV pela técnica de imunodifusão em gel de ágar (IDGA) seguindo o protocolo recomendado pelo fabricante (TECPAR ${ }^{\circledR}$, Curitiba-PR).

Paralelamente foi aplicado um questionário estruturado, formulado a partir da metodologia descrita por Thrusfield $^{14}$, com a finalidade de caracterizar os criatórios de bovinos Curraleiro e detectar a presença de possíveis fatores de risco relacionados à transmissão da $\mathrm{LB}$, tais como o manejo reprodutivo e sanitário, sistema de produção, aptidão do rebanho, presença de ectoparasitas hematófagos, trânsito e reposição dos $\operatorname{animais}^{6,12,15}$.

Os resultados foram analisados por estatística descritiva com cálculo da taxa de ocorrência por Estado, rebanho e animais de acordo com o sexo e a faixa etária. As faixas etárias foram definidas como: A (0 a 6 meses), B (7 a 12 messes), C (13 a 24 meses), D (25 a 36 meses), E (37 a 48 meses) e F (acima de 48 meses). A análise de frequências foi elaborada pelo teste de Qui-quadrado e regressão logística de dados com distribuição binomial, utilizando o programa SAS v.9.1 (Statistical Analysis Software Institute, Cary, North Carolina, USA) ${ }^{16} \mathrm{e}$ significância a 5\%.

\section{RESULTADOS E DISCUSSÃO}

A ocorrência de LB, considerando todas as 1051 amostras avaliadas foi $21,1 \%$ (222/1051); para o Estado de Goiás, foi 15,3\% (86/562). Em duas propriedades não foram identificados animais sororreagentes e a maior frequência encontrada nos diferentes rebanhos amostrados foi de $27,1 \%$. No Estado do Tocantins, foi observado um índice de 27,8\% (136/489) de sororreagentes e houve uma variação entre 2,5 e $66,7 \%$ entre as propriedades amostradas (Tabela 1). De acordo com as análises estatísticas, a frequência de sororreagentes no Tocantins foi significativamente maior que em Goiás $\left(\chi^{2}=24,55 ; p<0,01\right)$ com uma chance maior de ocorrer positividade nesse local $(\mathrm{OR}=2,39, \mathrm{CI}=0,217-0,785, \mathrm{p}<0,01)$.

De acordo com a classificação proposta por Shettigara et al. ${ }^{17}$, constatou-se que os rebanhos goianos apresentaram algumas propriedades com baixas taxas de infecção pelo VLB $(<10 \%)$, sendo a maioria com taxas médias (11 a 30\%). Em contrapartida, a maioria das propriedades do Tocantins apresentou altas taxas de sororreatividade, com valores acima de $30 \%$. Isso implica diretamente numa maior viabilidade de implantação de um programa de controle e erradicação da LB nos rebanhos do Estado de Goiás, por apresentarem taxas de ocorrência menores.

Vários inquéritos sorológicos em bovinos foram feitos nos Estados brasileiros, com finalidade de determinar a taxa de ocorrência de animais sororreagentes para o VLB e apontaram que o agente está bastante distribuído geograficamente, com valores que variaram de zero a $70 \%^{12}$. A variedade de resultados encontrados pode estar associada às diferenças entre as técnicas de diagnóstico utilizadas, tipos raciais e manejo empregado na criação $^{18}$. Nesse sentido, os resultados observados no presente estudo foram comparados àqueles obtidos em condições semelhantes.

As frequências encontradas em rebanhos Curraleiros foram menores que os índices descritos para gado leiteiro em Goiás ${ }^{19}$. Embora a raça Curraleiro tenha aptidão mista, a criação dos animais é predominantemente extensiva, sendo esperado um menor número de sororreagentes, tendo em vista que a aglomeração aumenta a sua frequência nos rebanhos ${ }^{20}$. Os dados encontrados neste estudo confirmam os resultados apontados por Silva ${ }^{6}$ de que baixos coeficientes de soropositividade nesses animais podem ser justificados pelo sistema extensivo de criação e o isolamento dos rebanhos.

Apesar de ter sido amostrado um número menor de machos em relação ao de fêmeas, foi 
observada sororreatividade significativamente maior nas fêmeas $(23,3 \%, 198 / 852)$ que em machos $(11,8 \%, 23 / 195)$. Estes resultados diferem dos apresentados por Silva ${ }^{6}$ que, mesmo tendo detectado um número maior de reatividade em fêmeas Curraleiras no Piaú, não encontrou diferença significativa entre sexo, e por Amoril ${ }^{6}$, que detectou maior risco de sororreatividade em bovinos machos. Birgel Jr et al. ${ }^{18}$ destacaram que, dentre os vários fatores que propiciam diferenças entre as frequências de ocorrência entre machos e fêmeas, encontra-se o manejo. A maior frequência observada nas fêmeas pode ser explicada em função de práticas de manejo que são exclusivas delas, como é o caso da vacinação contra brucelose bovina, quando existe, então, oportunidade de infecção pelo VLB pela utilização da mesma agulha para vários animais.

Tabela 1 - Localização dos rebanhos amostrados, número de amostras colhidas, número de amostras positivas e frequência de soropositividade no teste de IDGA para LB em rebanhos bovinos da raça Curraleiro nos Estados de Goiás (1 a 11) e Tocantins (12 a 23), 2006

\begin{tabular}{|c|c|c|c|}
\hline Rebanho & $\begin{array}{c}\mathbf{N}^{\circ} \text { de } \\
\text { amostras }\end{array}$ & $\begin{array}{c}\mathbf{N}^{\circ} \text { de } \\
\text { sororreagentes }\end{array}$ & $\begin{array}{c}\% \text { de } \\
\text { sororreagentes }\end{array}$ \\
\hline \multicolumn{4}{|l|}{ Goiás } \\
\hline 1 & 30 & 4 & 13,3 \\
\hline 2 & 36 & 7 & 19,4 \\
\hline 3 & 63 & 6 & 9,5 \\
\hline 4 & 20 & 0 & 0,0 \\
\hline 5 & 75 & 5 & 6,7 \\
\hline 6 & 49 & 7 & 14,3 \\
\hline 7 & 92 & 25 & 27,2 \\
\hline 8 & 81 & 16 & 19,7 \\
\hline 9 & 43 & 7 & 16,3 \\
\hline 10 & 13 & 0 & 0,0 \\
\hline 11 & 60 & 9 & 15,0 \\
\hline Total & 562 & 86 & 15,3 \\
\hline \multicolumn{4}{|l|}{ Tocantins } \\
\hline 12 & 25 & 9 & 36,0 \\
\hline 13 & 29 & 16 & 55,2 \\
\hline 14 & 8 & 3 & 37,5 \\
\hline 15 & 3 & 2 & 66,7 \\
\hline 16 & 4 & 2 & 50,0 \\
\hline 17 & 6 & 2 & 33,3 \\
\hline 18 & 70 & 36 & 51,4 \\
\hline 19 & 17 & 2 & 11,8 \\
\hline 20 & 111 & 9 & 8,1 \\
\hline 21 & 76 & 21 & 27,6 \\
\hline 22 & 40 & 1 & 2,5 \\
\hline 23 & 100 & 33 & 33,0 \\
\hline Total & 489 & 136 & 27,8 \\
\hline
\end{tabular}

Na Tabela 2 está demonstrada a frequência de sororreagentes por faixa etária, sendo que houve diferença estatística significativa entre as faixas etárias B e $\mathrm{F}(\mathrm{p}<0,05)$. O aumento na frequência de sororreagentes com o avançar da idade foi semelhante ao ocorrido em rebanhos de corte nos Estados do Piaú, de Goiás, de Minas Gerais e do Amazonas $^{6,21}$. Este fato está relacionado à maior probabilidade de contato entre animais infectados e não infectados, por permanecerem mais tempo no rebanho.

A frequência de sororreagentes na faixa $\mathrm{A}$ $(13,5 \%)$, caracterizada por bezerros recém-nascidos até seis meses de idade, justifica-se pela interferência de anticorpos colostrais circulantes que pode resultar em reações falso-positivas. Os níveis séricos dos bezerros tendem a se reduzir a partir dos seis meses de idade $^{22}$; por este motivo, recomenda-se interpretar 
como infectados bezerros reagentes à IDGA na faixa etária acima de seis meses, idade na qual os níveis de imunoglobulinas colostrais estão bastante reduzidos no sangue e não são mais detectadas pelo limiar desta prova diagnóstica ${ }^{6}$. No presente trabalho, este fato pôde ser comprovado pela diminuição do número de sororreagentes na faixa etária $\mathrm{B}(5,5 \%)$, que representa os bezerros acima de seis meses de idade (Tabela 2).

A introdução das práticas de vacinação e vermifugação no momento da desmama pode ter contribuído para o aumento de sororreatividade na faixa C (16,1\%), pois nessas propriedades a desmama ocorre naturalmente em torno de 9 e 11 meses de idade para fêmeas e machos, respectivamente ${ }^{23}$.

Tabela 2 - Frequência de sororreagentes no teste de IDGA para LB em bovinos da raça Curraleiro nos Estados de Goiás e Tocantins em relação à faixa etária, 2006

\begin{tabular}{lccc}
\hline Faixa etária & Número de animais & Número de sororreagentes & Frequência (\%) \\
\hline A - 0 a 6 meses & 118 & 16 & 13,5 \\
B -7 a 12 meses & 108 & 6 & $5,5 *$ \\
C - 13 a 24 meses & 161 & 26 & 16,1 \\
D - 25 a 36 meses & 150 & 16 & 10,7 \\
E - 37 a 48 meses & 233 & 38 & 16,3 \\
F - acima de 48 meses & 281 & 120 & $42,7 *$ \\
Total & 1051 & 222 & 21,1 \\
\hline
\end{tabular}

*diferença estatisticamente significativa entre as faixas etárias B e $\mathrm{F}$ a um nível de 5\%.

A distribuição dos animais sororreagentes ampliou-se a partir dos 36 meses de idade, sugerindo que alguns fatores envolvidos na disseminação do agente não puderam ser determinados e apontando para a necessidade de uma investigação aprofundada sobre a epidemiologia da LB.

Del Fava e Pituco ${ }^{12}$ citaram como condições de risco a aglomeração de animais, a introdução de indivíduos no rebanho e a intensificação do manejo com atividades de vacinação, cirurgias, premunição e palpação retal. Alguns autores citaram que a presença de insetos hematófagos pode estar envolvida na disseminação da $\mathrm{LB}^{6,15}$. Esses fatores de risco foram pouco expressivos ou inexistentes nas propriedades de Curraleiro utilizadas no presente estudo.

As informações fornecidas pelos questionários revelaram que os rebanhos de bovinos Curraleiro estão em propriedades rurais de pecuária de corte extensiva, com reprodução por monta natural sem estação de monta, com todas as categorias animais compartilhando o mesmo local e recebendo cuidados sanitários mínimos, como vacinação, vermifugação e mineralização. Todos os entrevistados mencionaram que os animais são longevos e apontaram que as principais causas de mortalidade em animais adultos são acidentes ofídicos e senilidade.

Alguns parâmetros puderam ser analisados estatisticamente como possíveis fatores de risco, como a presença de insetos hematófagos (carrapatos e mosca dos chifres) em maior ou menor intensidade. Além desses fatores, analisaram-se o trânsito de animais provenientes de rebanhos da região, introduzidos em algumas propriedades para reposição de reprodutores, assim como a presença de rebanhos "fechados", ou seja, quando não havia a introdução de bovinos e a reposição era feita com animais próprios. A análise de regressão logística não detectou significância para nenhum desses fatores como sendo de risco ( $p>0,05)$.

De acordo com Monti et al. ${ }^{24}$, o fato de a LB ser uma doença crônica, com baixos índices de mortalidade, combinado ao longo tempo de permanência no rebanho e à precocidade com que os animais se infectam, são determinantes na dinâmica e controle dessa enfermidade na população, porém muito variáveis entre as propriedades. Nos rebanhos de bovinos Curraleiros, esses aspectos têm importância, pois os animais permanecem no rebanho durante toda a vida, sendo muito pequena a taxa de descarte e reposição de animais oriundos de outros rebanhos.

A ausência de sinais clínicos característicos 
da infecção pelo VLB nos animais estudados e a interferência da resistência genética na imunopatogenia dessa enfermidade apontam para um aspecto importante a ser abordado, pois a seleção de indivíduos portadores de genes de resistência para LB pode ser uma ferramenta fundamental para o controle/erradicação dessa infecção ${ }^{25}$ e para a conservação do patrimônio genético da raça Curraleiro.

\section{CONCLUSÕES}

$\mathrm{O}$ presente estudo permitiu concluir que a LEB está presente nos bovinos da raça Curraleiro, tendo sido a frequência de ocorrência de sororreatividade significativamente maior no Estado de Tocantins $(27,8 \%)$ que em Goiás $(15,30 \%)$. As fêmeas e indivíduos com idade acima de 48 meses apresentaram maior risco de infecção; todavia, nem a presença de insetos hematófagos ou a introdução de novos animais no rebanho foram considerados fator de risco significativo para infecção.

\section{AGRADECIMENTOS}

Os autores agradecem aos criadores que consentiram na obtenção dos espécimes clínicos deste estudo, à equipe de funcionários e auxiliares pela contribuição nas atividades de campo e procedimentos laboratoriais, bem como ao Ministério da Integração Nacional pelo financiamento do projeto e do CNPq pela bolsa de doutorado.

\section{REFERÊNCIAS}

1. Mariante, AS., Egito, AA. Animal genetic resources in Brazil: result of five centuries of natural selection, Theriogenology, 2002; 57:223-235.

2. Netestado. Animais adaptam-se bem às regiões secas [Internet], O Estado de São Paulo, São Paulo, 07 agosto. 1998 [acesso em: 26 nov. 2002], Disponível em: http://acervo.estadao.com.br/pagina/\#!/19981007-38340spo-0089-agr-g13-not..

3. Boaventura VM, Fioravanti MCS., Juliano RS. Gado Curraleiro: relação dos criadores e aspectos gerais da raça. 1st ed. Goiânia: Sebrae-GO, 2005. 80 p. Portuguese.

4. Hodges J. The management of global animal genetic resources. Proceedings of an FAO Expert Consultation, Rome, Italy, 1992. 263p. Disponível em http://www.fao.org/docrep/006/t0665e/t0665e00.HTM

5. Fioravanti MCS, Juliano RS, Costa GL, Abud LJ, Cardoso VS, Carpio MG, Costa MFO. Conservación del bovino Curraleiro: cuantificación del censo y caracterización de los criadores. Animal Genetic
Resources, 2011; 48:109-116.

6. Pereira, ALM, Costa AF, Veschi JLA, Almeida, KS. Soroprevalência da leucose enzoótica Bovina: Revisão de literatura. Revista Científica Eletronica de Medicina Veterinária. 2013[acesso em 08 set 2014], Disponível em: http://faef.revista.inf.br/imagens_arquivos/arquivos_desta que/XivYV78xSxgLb1J_2013-8-13-18-30-0.pdf

7. Garcia M., D'Angelino JL, Benesi FJ, Birgel EH, Marçal WS. Avaliaçäo do leucograma de fêmeas da raça Holandesa naturalmente infectadas pelo Vírus da Leucose Bovina. Pesquisa Veterinária Brasileira, 1991; 11 (3): 6164.

8. Birgel Jr EH, Salvatore LCA, Neves FS, Mirandola RMS, Souza PM, Birgel EH. Dinâmica das proteínas séricas de fêmeas bovinas da raça holandesa naturalmente infectadas pelo vírus da leucose dos bovinos. Ciência Rural, 2001; 31 (4): 615-619.

9. Azedo MR, Massoco CO, Blagitz, MG, Sanches BGS, Souza FN, Batista CF, Sakai M, Sá-Rocha. LC, Kfoury Junior JR, Stricagnolo CR, Benesi FJ, Della Libera AMMP. Influência da leucose enzoótica bovina na função fagocítica de leucócitos circulantes em animais manifestando linfocitose persistente. Brazilian Journal of Veterinary Research and Animal Science, 2008; 43 (5): 390-397.

10. D'Angelino JL, Garcia M, Birgel EH. Productive and reproductive performance in bovine leukosis virusinfected cattle. Journal of Dairy Research, 1998a; 65: 693695.

11. Ott SL.; Johnson R, Wells SJ. Association between bovine-leukosis virus seroprevalence and herd-level productivity on US dairy farms. Preventive Veterinary Medicine, 2003; 61: 249-262.

12. Del Fava C, Pituco EM. Infecção pelo vírus da leucemia bovina (BLV) no Brasil. O Biológico, São Paulo, 2004; 66 (1/2): 1-8.

13. MacDiarmid SC, Pharo HJ. Risk analysis: assessment, management and Communication. Review Scientific of Technology of International Epizooty, 2003; 22: 397-408.

14. Thrusfield M. Veterinary Epidemiology. 2.ed. Oxford: Blackwell Science. 1995. 479 p.

15. Buxton BA, Schultz RD. Factors affecting the infectivity of lymphocytes from cattle with bovine leukosis virus. Canadian Jounal Comparative Medicine, 1984; 48: 365-369.

16. SAS, Institute. Statistical Analysis System: user guide [CD-ROM]. Version 9. Cary (NC): SAS Insitute Inc., 2005.

17. Fernandes CHC, Melo LEH, Tenório TGS, Mendes EI, Fernandes ACC, Ramalho TRR, Moura Sobrinho PA, Mota RA. Soroprevalência e fatores de risco da infecção pelo vírus da leucose dos bovinos em rebanhos leiteiros da região Norte do Estado do Tocantins, Brasil. Arquivos do Instituto Biológico de São Paulo, 2009; 76 (3): 327-334. 
18. Birgel Jr EH, Dias WMC, Souza RM, Pogliani FC, Birgel DB, Birgel EH. Prevalência da infecção pelo vírus da Leucose dos bovinos, em animais da raça Simental, criados no estado de São Paulo. ArsVeterinária, 2006; 22 (2): 122-129.

19. Andrade JRA, Almeida MMR. Prevalência da Leucose Enzoótica Bovina na Bacia Leiteira de Goiânia, Goiás. Hora Veterinária, 1991; 10, (60): 49-53.

20. D’Angelino JL, Garcia M, Birgel EH. Epidemiological study of enzootic bovine leukosis in Brazil. Tropical Animal Health and Production, 1998b;. 30: p. 13-15.

21. Carneiro PAM, Araújo WP, EH, Souza KW. Prevalência da infecção pelo vírus da leucose dos bovinos em rebanhos leiteiros criados no estado do Amazonas, Brasil. Acta Amazônica, 2003; 33 (1): 111-125.

22. Acres SD. Feeding heat-treated antibody-positive colostrum helps prevent the spread of blv to newborn calves. The Colostrum Counsel, 2013 [acesso em 14 set
2014].

Disponivel

em

http://www.syrvetcanada.ca/img/product/description/The

$\% 20$ Colostrum\%20Counsel\%20-

$\% 20$ February\%202013.pdf

23. Castanheira M, MacManus CM, Paula Neto JB, Paranhos da Costa MJR, Mendes FDC, Sereno JRB, Bértoli CD, Fioravanti MCS. Maternal offspring behaviour in Curraleiro Pé Duro naturalized cattle in Brazil. Revista Brasileira de Zootecnia, 2013, 42 (8):584591.

24. Monti GE, Frankena, K, De Jong MCM. Evaluation of natural transmission of bovine leukaemia vírus within dairy herds of Argentina. Epidemiology and Infection, 2007; 135: 228-237.

25. Juliarena MA, Poli M, Sala L, Ceriani C, Gutierrez S, Dolcini G, Rodriguez EM, Mariño B, Rodríguez-Dubra C, Esteban EN. Association of BLV infection profiles with alleles of BoLA-DRB3.2 gene. Animal Genetics, 2008; 69: 432-438. 